\title{
ESTOQUE DE CARBONO EM SOLOS SOB PASTAGENS CULTIVADAS NA BACIA HIDROGRÁFICA DO RIO PARANAIÍBA
}

\section{Carbon storage in soils of cultivated pastures in the Parnaiba River basin}

\author{
Roberto Rosa \\ Universidade Federal de Uberlândia, Uberlândia, Minas Gerais, Brasil \\ rrosa@ufu.br \\ Edson Eyji Sano \\ EMBRAPA, Brasília, Distrito Federal, Brasil \\ edson.sano@gmail.com \\ Jussara dos Santos Rosendo \\ Universidade Federal de Uberlândia, Ituiutaba, Minas Gerais, Brasil \\ jussara@pontal.ufu.br
}

Artigo recebido em 14/11/2013 e aceito para publicação em 24/01/2014.

RESUMO: O trabalho teve como objetivo avaliar o estoque de carbono nos solos sob pastagens cultivadas, na bacia hidrográfica do Rio Paranaíba. Para estimar a quantidade de carbono estocado foram coletadas 80 amostras de solo, de forma aleatória, sendo 40 em pastagens degradadas (PD) e 40 em pastagens melhoradas (PM), nas profundidades de $0-5 \mathrm{~cm}, 5-10 \mathrm{~cm} ; 10-20 \mathrm{~cm}$ e $20-30 \mathrm{~cm}$. As variáveis do solo analisadas foram textura, densidade; teor de carbono total (\%) e estoque de carbono (Mg/ha). Em média as pastagens (melhorada e degradada) ocupam áreas de solo com características granulométricas semelhantes, no entanto, a densidade do solo sob pastagem melhorada é menor do que a dos solos sob pastagem degradada. A densidade aumenta com o aumento da profundidade do solo, em ambas as pastagem. $\mathrm{O}$ teor de carbono diminui com a profundidade do solo, independente das condições da pastagem. Em média, a pastagem melhorada apresenta valor mais elevado de carbono do solo do que a pastagem degradada, em todas as profundidades analisadas. A camada superficial $(0-5 \mathrm{~cm})$ apresenta o maior teor de carbono (média), tanto para pastagem melhorada $(2.60 \%)$ quanto para pastagem degradada $(1.90 \%)$. Se considerarmos todas as camadas analisadas $(0-30 \mathrm{~cm})$ a pastagem melhorada possui um estoque de carbono de $68.28 \mathrm{Mg} / \mathrm{ha}$, enquanto que a pastagem degradada possui $59.35 \mathrm{Mg} / \mathrm{ha}$. Os dados comprovam que uma pastagem bem manejada consegue reter no solo, na profundidade de $0-30 \mathrm{~cm}, 15 \%$ a mais de carbono do que em uma pastagem degradada, ressaltando a importância do manejo das pastagens como forma de retirar carbono da atmosfera e armazenar no solo. Em um cenário onde toda a pastagem degradada fosse convertida em melhorada, a bacia teria um potencial de aumento do estoque de carbono no solo da ordem de $41 \mathrm{Tg}$. Palavras-chave: pastagens; estoque de carbono; bacia do Rio Paranaíba

ABSTRACT: This study aimed to assess the soil carbon stock under cultivated pastures in the Parnaíba River basin. A set of 80 soil samples were collected randomly in the basin, 40 in degraded pastures and 40 in improved pastures, at the following depths: $0-5,5-10,10-20$ and 20-30 $\mathrm{cm}$. Soil texture, bulk density, total carbon content (\%) and 
carbon stock $(\mathrm{Mg} / \mathrm{ha})$ were the variables considered. Overall, both degraded and improved pastures occupy areas of similar soil texture, however, the soil bulk density under improved pastures presented lower values than that from soils under degraded pasture. The bulk density increased with the increasing soil depth in both types of pastures. The soil carbon content decreased with soil depth regardless of the pasture's management condition. On average, improved pastures, in comparison with degraded pastures, presented higher soil carbon contents at all considered soil depths. The surface layer $(0-5 \mathrm{~cm})$ showed the highest soil carbon contents on average and for both improved pastures (2.6\%) and degraded pastures (1.9\%). Considering all soil depths $(0-30 \mathrm{~cm})$, improved pastures had an average soil carbon content of $68.28 \mathrm{Mg} / \mathrm{ha}$, while degraded pastures presented an average soil carbon content of $59.35 \mathrm{Mg} / \mathrm{ha}$. Well-managed pastures can store carbon throughout the entire soil depth considered in this study $(0-30 \mathrm{~cm})$ upt to $15 \%$ more carbon than in degraded pastures, emphasizing the importance of pasture management as a way of seeking carbon from the atmosphere and stock it in the soil. In a scenario where all degraded pastures are converted into improved pasture, we can have an additional $41 \mathrm{Tg}$ of carbon stocked in the Parnaiba river basin.

Keywords: pastures; carbon stocks; Paranaiba River basin

\section{INTRODUÇÃO}

As atividades humanas são reconhecidamente assumidas como causadoras de alterações ambientais. $\mathrm{O}$ aumento da concentração de $\mathrm{CO}_{2}$ na atmosfera e sua relação com o aquecimento global, tem sido amplamente debatido junto à comunidade científica e nos meios de comunicação. O Brasil é reconhecido como um dos grandes responsáveis pela emissão de gases estufa em decorrência do desmatamento. Nas últimas décadas este fato tem se intensificado mediante, principalmente, a expansão das atividades agrícolas, especialmente na região dos Cerrados (IPCC, 2007).

Atualmente um dos principais desafios científicos e tecnológicos para mitigar os efeitos da degradação tem sido a restauração não só da estrutura, mas também do funcionamento do sistema degradado, no entanto, esforços nessa linha só serão bem sucedidos se puderem agregar benefícios econômicos e sociais aos benefícios ecológicos.

$\mathrm{O}$ constante aumento de gases carbônicos na atmosfera, particularmente o $\mathrm{CO}_{2}$ e o $\mathrm{CO}$, tem levantado a discussões sobre as alternativas que poderiam diminuir a liberação destes gases visando minimizar o impacto no meio ambiente. Uma alternativa que vem sendo discutida como uma opção viável para solucionar, em parte, a emissão de carbono na atmosfera, trata-se do seqüestro e armazenamento de carbono atmosférico, o que pode ser feito pela vegetação.

As pastagens cobrem cerca de dois terços de toda a área agricultável do globo terrestre. No Brasil, as pastagens ocupam cerca de três quartos da área agrícola nacional, ou seja, estima-se que o Brasil tenha cerca de 164 milhões de hectares de pastagens cultivadas, no entanto, aproximadamente $50 \%$ desse total já se encontram em algum estádio de degradação, com níveis de produtividade de forragem bastante baixos, reflexos da degradação, resultante de manejo inadequado (MMA, 2007).

A degradação da pastagem faz com que haja redução na produtividade primária líquida, perda de matéria orgânica do solo e/ou emissão de $\mathrm{CO}_{2}$ para atmosfera. Acredita-se que com um manejo adequado as pastagens podem contribuir significativamente no combate ao aumento do efeito estufa potencializando o seqüestro de carbono pelo solo. Nesse cenário, a restauração de ecossistemas degradados vem ganhando importância e recebendo investimentos por meio de cooperação internacional, para restauração e/ou reabilitação dessas áreas degradadas, tendo como enfoque a remoção do carbono atmosférico.

A preocupação atual é sobre o rumo que nossa pecuária de corte deve tomar, sabendo-se que na realidade algumas práticas de manejo tradicionais devem ser abandonadas, pois prejudicam o ambiente e a produtividade do sistema. Para uma população em constante crescimento, a FAO (2013) estima que a demanda por alimentos, em 2050 , será $70 \%$ maior da que temos hoje e o desafio é como produzir mais conservando o meio ambiente e melhorando a qualidade de vida da população. Neste cenário, cabe à cadeia agropecuária buscar alternativas que resultem 
em ganho de eficiência minimizando seus impactos sobre o meio ambiente.

Face ao exposto, o presente trabalho teve como objetivo avaliar o estoque de carbono armazenado sob pastagens degradadas e em pastagens melhoradas, procurando comparar os resultados encontrados, bem como, simular a quantidade adicional de carbono que pode ser estocado nos solos sob pastagens cultivadas da bacia em um cenário em que todas as pastagens estejam com capacidade plena de produção vegetal.

\section{A ÁREA DE ESTUDO}

A Bacia Hidrográfica do rio Paranaíba é a segunda maior unidade hidrográfica da Região Hidrográfica do Paraná, com 25.4 \% de sua área, que corresponde a uma área de drenagem de 223532.7 $\mathrm{km}^{2}$, abrangendo parte dos estados de Goiás (63.2 \%), Minas Gerais (31.7\%), Mato Grosso do Sul (3.4 \%) e Distrito Federal (1.7\%). O rio Paranaíba, cuja nascente ocorre no município de Rio Paranaíba-MG, na Serra da Mata da Corda, percorre cerca de 1160 $\mathrm{km}$ até sua foz, no encontro com o Rio Grande, desde a cota $1100 \mathrm{~m}$ até $328 \mathrm{~m}$, nível este do lago da hidrelétrica de Ilha Solteira. A população da bacia é de cerca de 8.5 milhões de habitantes, sendo que aproximadamente $92 \%$ vivem em áreas urbanas. Esta população esta distribuída em 193 municípios pertencentes a quatro Unidades da Federação: Goiás (133 municípios), Minas Gerais (55 municípios), Mato Grosso do Sul (4 municípios) e o Distrito Federal (Figura 1).

Figura 1. Localização da bacia hidrográfica do Rio Paranaíba
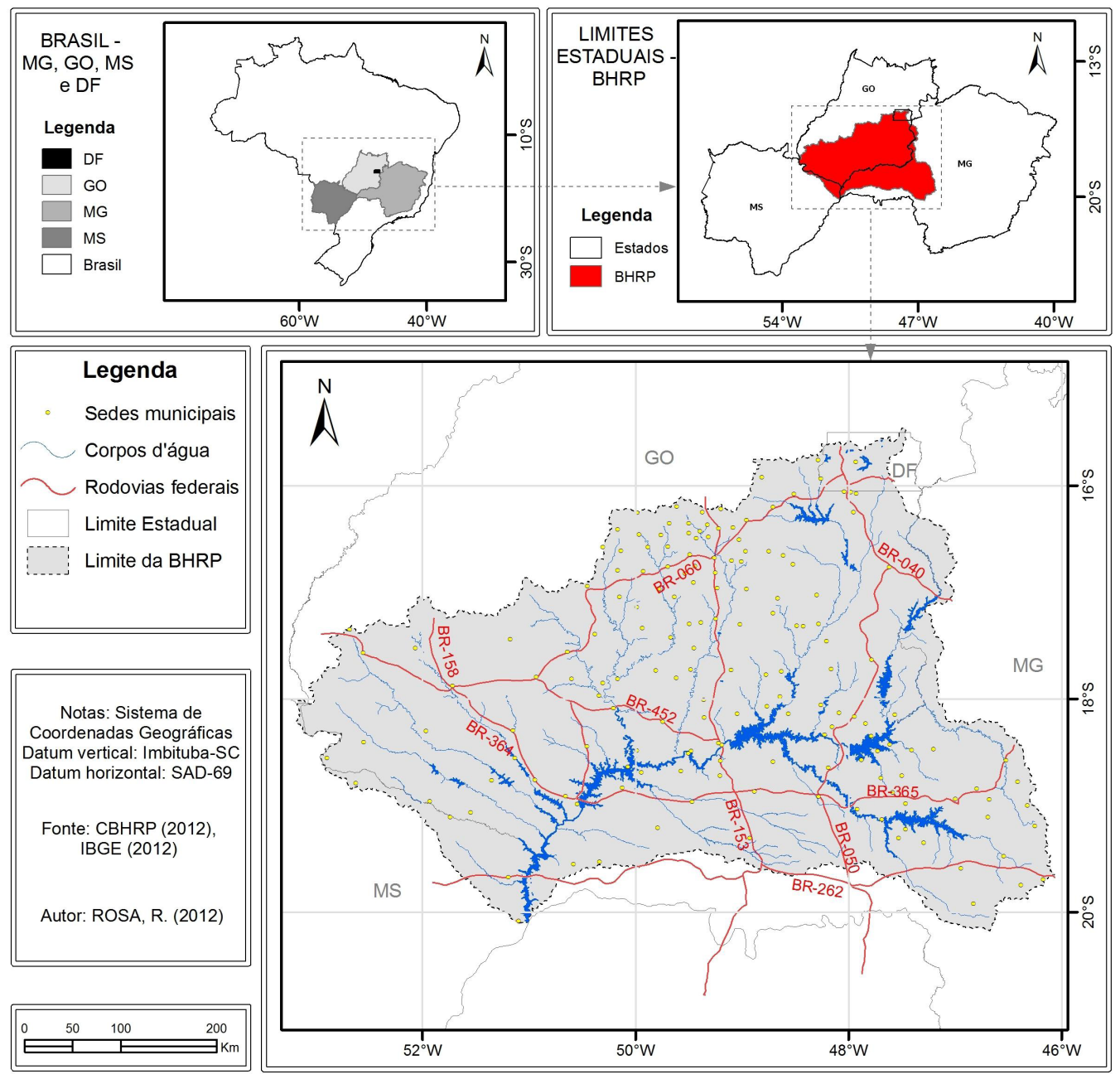

Org. dos autores 
A partir da análise dos dados (2000 a 2010) de 18 estações meteorológicas localizadas dentro da bacia, verifica-se que a mesma possui clima tropical, com temperatura média mensal superior a 18 ${ }^{\circ} \mathrm{C}$, e amplitude térmica inferior a $5{ }^{\circ} \mathrm{C}$, podendo ser classificado como Aw segundo Koppen. Possui uma sazonalidade marcante com período seco muito bem definido (maio a setembro), e chuvoso de outubro a abril, com precipitações médias variando entre 1400 a $1800 \mathrm{~mm}$ ano.

$\mathrm{Na}$ porção sudoeste da bacia concentram-se as menores altitudes topográficas da área, principalmente ao longo do canal principal do rio Paranaíba e o médio a baixo curso de seus principais afluentes, já os pontos de maior altitude estão localizados na margem nordeste.

As maiores declividades se concentram na porção oriental da bacia, onde predominam os modelados de dissecação do tipo tabular, com densidade muito fraca de aprofundamento da drenagem e conseqüente prevalecimento do escoamento superficial. Esta porção da bacia com maiores declividades está presente geomorfologicamente nos chamados Planalto do Distrito Federal e Planalto Rebaixado de Goiás, compreendendo materiais geológicos representados por rochas metamórficas e sedimentos silicificados. Já os terrenos de baixa declividade estão localizados principalmente ao longo do curso dos rios Verde, Turvo e dos Bois, relacionados à existência de materiais geológicos pertencentes à Formação Serra Geral, e nas bacias hidrográficas dos afluentes do médio e baixo curso do rio Paranaíba, relacionados com a presença de rochas sedimentares vinculadas à Formação Vale do rio do Peixe.

A partir dos levantamento realizado pelo Projeto RADAMBRASIL verifica-se que os solos predominantes na bacia são os latossolos (65\% da área), cambissolos (15\%), podzólicos (8\%) e o restante da área (12\%) é ocupado com outros tipos de solo, dentre os quais destam-se areias quartzosas, litólicos, glei pouco húmico e terra roxa. São solos predominantes (latossolos) possuem baixa fertilidade natural e boas propriedades físicas. Ocorrem em relevo plano a suave ondulado, onde favorecem a mecanização.

A vegetação original da bacia era típica do Bioma Cerrado, atualmente bastante descaracterizada, composta por fitofisionomias que englobam formações florestais, savânicas e campestres. As formações florestais são representadas por Mata Ciliar, Mata de Galeria, Mata Seca e Cerradão. As formações savânicas são compostas por árvores e arbustos espalhados sobre um estrato gramino-lenhoso onde não há formação de dossel contínuo, são representadas pelo Cerrado (denso, típico, ralo e rupestre), Vereda, Parque de Cerrado e Palmeiral.

As formações campestres são formadas pelo predomínio de espécies herbáceas e algumas arbustivas, observando-se a inexistência de árvores na paisagem, representadas pelo campo sujo, limpo e rupestre. Destaca-se que não há limites definidos entre uma fisionomia e outra, assim, formas intermediárias podem ocorrer entre elas. Outra característica é que a vegetação apresenta fenologia marcadamente sazonal, com incremento da biomassa na estação das chuvas (outubro a abril) e dessecação das partes aéreas na estação seca (maio a setembro), o que favorece a ocorrência de incêndios naturais e, também, decorrentes da ação antrópica (SANO, et. al. 2010).

As atividades econômicas da bacia são bastante diversificadas, com destaque na pecuária, produção de soja, milho, algodão, café e mais recentemente cana-de-açúcar. Além disso, a bacia é conhecida, principalmente pelo potencial hidrelétrico, responsável pela geração de grande parte da energia de Minas Gerais e Goiás. De acordo com a Agência Nacional de Águas (2011), a bacia responde por cerca de $70 \%$ da energia elétrica consumida em Minas Gerais, permitindo, também, que as terras agricultáveis ao longo das margens do rio Paranaíba possuam os maiores índices de crescimento de áreas irrigadas do país.

\section{REFERÊNCIAL TEÓRICO}

O carbono é o elemento químico fundamental dos compostos orgânicos, que circulam através dos oceanos, da atmosfera, do solo, e subsolo. Estes são considerados depósitos (reservatórios) de carbono. O carbono passa de um depósito a outro através de processos químicos, físicos e biológicos. O solo é um componente fundamental no processo de emissão e seqüestro de carbono. Em escala global os principais reservatórios de carbono são os oceanos seguidos 
pelos depósitos de combustíveis fósseis, os solos, a atmosfera e a vegetação. Há mais carbono nos solos (1720 Pg C), em relação ao presente na atmosfera (740 Pg C).

Segundo Eswaran et. al. (1993), estima-se que a quantidade de carbono estocada no solo, até $1 \mathrm{~m}$ de profundidade, é de aproximadamente $1576 \mathrm{Pg}$ de C. Segundo Cerri et. al. (2006), o estoque de carbono nos primeiros $30 \mathrm{~cm}$ é de aproximadamente $800 \mathrm{Pg}$ de C.

Neste contexto, o solo aparece com uma alternativa para o seqüestro do carbono presente na atmosfera constituindo-se em uma alternativa para mitigar o aumento das concentrações de gazes do efeito estufa contribuindo assim para redução do aquecimento global e das mudanças climáticas.

A atmosfera é o menor e o mais dinâmico dos reservatórios do ciclo do carbono. Entretanto, todas as mudanças que ocorrem neste reservatório têm uma estreita relação com as mudanças do ciclo global de carbono e do clima. Grande parte do carbono presente na atmosfera ocorre na forma de dióxido de carbono $\left(\mathrm{CO}_{2}\right.$, também conhecido como gás carbônico). Qualquer atividade relacionada ao uso da terra que modifique a quantidade de biomassa na vegetação e no solo tem o potencial de alterar a quantidade de carbono armazenada e emitida para a atmosfera, o que influencia diretamente a dinâmica do clima da terra.

A troca de carbono entre o reservatório terrestre e o atmosférico é o resultado de processos naturais da fotossíntese e respiração, e da emissão de gases causados pela ação humana. A captura de carbono através da fotossíntese ocorre quando as plantas absorvem energia solar e $\mathrm{CO}_{2}$ da atmosfera, produzindo oxigênio e hidratos de carbono, que servem de base para seu crescimento. Através deste processo as plantas fixam o carbono na biomassa da vegetação, e junto com seus resíduos (madeira morta e serapilheira), um estoque natural de carbono. O processo inverso ocorre com a emissão de carbono através da respiração das plantas, animais, e pela decomposição orgânica. Acrescenta-se à está, as emissões devido ao desmatamento, queimadas, gases industriais e queima de combustíveis fósseis.

A conversão de um sistema natural em pastagem pode ter uma importante influencia no destino do carbono estocado no solo. Em solos sobre a vegetação natural a preservação da matéria orgânica tende a ser máxima, pois o revolvimento do solo é mínimo sendo o aporte de carbono nas florestas mais elevado do que em áreas de pastagem (NOBRE; GASH, 1997), no entanto quando a vegetação original é o cerrado às reduções do carbono orgânico tem sido menores, podendo até mesmo ocorrer à manutenção dos teores iniciais (SILVA, 1997). Já em áreas agrícolas (submetidas ao plantio convencional) os teores de matéria orgânica, em geral, diminuem, já que as frações orgânicas são mais expostas ao ataque de microrganismos, em função do maior revolvimento e desestruturação do solo.

O carbono presente no solo está amplamente relacionado ao processo de decomposição da biomassa pelas atividades bacterianas. Parte do carbono presente no solo volta à atmosfera através do processo de mineralização do carbono orgânico. A outra parte do carbono orgânico é levada pelos rios até chegar aos oceanos, onde se deposita sob a forma de carbonatos $\left(\mathrm{CO}_{3}\right)$.

O ciclo do carbono pode ser considerado a "chave" para o entendimento das mudanças climáticas globais, contudo são necessários maiores estudos especialmente, da função da vegetação e dos solos neste processo, com destaque para os efeitos das mudanças no uso da terra. Mudanças no uso da terra alteram os processos biogeoquímicos do solo, com reflexos no estoque de carbono e no fluxo de gases entre o solo e a atmosfera. Dependendo das características da área e do sistema de manejo adotado, essas alterações podem representar uma mudança no papel do solo como reservatório de carbono.

Os três processos responsáveis pelo seqüestro de carbono nos solos são a humificação, a agregação e a sedimentação, enquanto que os processos responsáveis pelas perdas de carbono são a erosão, decomposição, volatilização e lixiviação (LAL et. al., 1998).

Nos diferentes sistemas de uso da terra, o carbono é liberado pela vegetação depois da sua derrubada e queima e, pelo solo depois das intervenções freqüentes no preparo do solo. Por outro lado, o uso de práticas de manejo pode potencialmente mitigar e reduzir as emissões de carbono, ou seja, seqüestrando-o, capturando-o e mantendo-o o maior tempo possível na biomassa, no solo e nos oceanos.

O carbono do solo está presente na forma 
orgânica e inorgânica. A forma orgânica equivale à maior reserva em interação com a atmosfera. $\mathrm{O}$ carbono orgânico presente no solo representa um balanço dinâmico entre a absorção de material vegetal morto e a perda por decomposição (mineralização). Geralmente, as concentrações de carbono orgânico do solo são mais altas nas camadas superficiais e diminuem exponencialmente conforme aumenta a profundidade. Recomenda-se medir o depósito de carbono do solo a profundidades de pelo menos $30 \mathrm{~cm}$, dividindo esta em horizontes. Esta é a profundidade em que provavelmente ocorrerão variações perceptíveis no depósito de carbono. O carbono armazenado no solo é calculado através da somatória do carbono armazenado em cada horizonte. Para estimar o carbono armazenado no solo é necessário medir a densidade aparente do solo a cada nível de profundidade (horizonte).

O teor de carbono orgânico no solo sob diferentes sistemas fornece informações importantes para avaliação da qualidade do solo. Atualmente cresce o interesse na identificação de sistemas de manejo de culturas e pastagens que promovam o aumento no estoque de carbono no solo. Estudos recentes, tem demonstrado, que pastagens bem manejadas no Cerrado possuem estoques de carbono igual ou até mesmo superiores do que os apresentados pelas diferentes fitofisionomias do cerrado (ROSENDO; ROSA, 2012; SILVA et. al. 2004), devido a um maior acúmulo de biomassa em pastagens do que na vegetação nativa do cerrado, no entanto, se as pastagens estão degradadas, produzem menores quantidades de serapilheira, matéria orgânica e biomassa nos solos.

Santos et. al. (2004) mostraram que fluxos de $\mathrm{CO}_{2}$ para atmosfera em uma área de pastagem na região do Cerrado foram superiores aqueles observados em uma área de cerradão sugerindo que os estoques de carbono e a produtividade em pastagens bem manejadas podem ser maiores do que a vegetação nativa.

Com a conversão da cobertura vegetal original em pastagens ocorre uma série de alterações nas propriedades físicas e químicas do solo, que podem ser de caráter positivo ou negativo, isto é, podem provocar a melhoria das propriedades físicas e químicas do solo, mas também podem acelerar a degradação dependendo do tipo de solo, da espécie vegetal e do sistema de manejo. A matéria orgânica nos solos normalmente decresce nos primeiros anos após a implantação das pastagens, podendo aumentar a seguir, dependendo do sistema de manejo adotado.

Em termos de estoque de carbono em solos sob pastagens cultivadas, o que existe são dados pontuais e com distribuição muito limitada nos seis biomas brasileiros. A título de exemplo, podem ser citados os estudos conduzidos por Moraes et al. (2002), Feigl (1995) e Cerri et al. (2007) na Amazônia; Silva et al. (2004), Frazão et al. (2010), Oliveira et al. (2004) e Corazza et al. (1999) no Cerrado; e Tarré et al. (2001) e Rangel e Silva (2007) na Mata Atlântica, Rosendo e Rosa (2012) na bacia do Rio Araguari - MG.

A conversão de áreas nativas para pastagens provoca alterações nos estoques de carbono no solo. Roscoe et al. (2001), estudando uma pastagem de 23 anos, observaram estoques de carbono semelhantes ao de uma vegetação nativa de Cerrado, porém, solos que apresentam baixa produtividade devido ao processo de degradação costumam apresentar redução nos estoques de carbono em comparação aos da vegetação nativa (Silva et al. 2004). Por outro lado, alguns trabalhos também mostram aumento nos estoques de carbono no solo após a conversão (CORAZZA et al. 1999; CHAPUIS LARDY et al. 2002; D'ANDREA et al 2002; Maia et al. 2009). Este fato pode ser atribuído à manutenção da produtividade da pastagem devido ao manejo, freqüentemente com a utilização de fertilizantes. Ogle et al. (2004) registraram um aumento de 17 $\%$ na matéria orgânica de solos tropicais quando a capacidade produtiva das pastagens foi recuperada.

Os resultados às vezes divergentes quanto aos estoques de carbono entre as pastagens e áreas nativas de Cerrado, podem ser em conseqüência das técnicas de manejo e do grau de degradação das pastagens. Dessa forma são necessários estudos mais detalhados para se obter resultados mais conclusivos, referentes aos estoques de carbono em pastagens bem manejadas (pastagem melhorada) e pastagens degradadas.

Atualmente, sabe-se que a diminuição na capacidade produtiva de pastagens reduz o estoque de carbono nos seus solos e, de maneira inversa, a recuperação dessa capacidade aumenta esses estoques. A textura do solo também exerce influência no estoque 
de carbono em solos sob pastagens. Estimativas nacionais, disponíveis na literatura, apresentam valores bastante variados.

Em termos de área geográfica ocupada, as pastagens cultivadas correspondem ao tipo de uso da terra mais importante no Brasil e a maior parte dessas pastagens não se encontra em plena capacidade de produção vegetal. Portanto, a recuperação da capacidade produtiva de biomassa de pastagens degradadas pode se constituir em uma alternativa viável para o país em termos de aumento de estoque de carbono e de mitigação de emissão de $\mathrm{CO}_{2}$ na atmosfera.

$\mathrm{O}$ manejo de pastagens tem sido citado como sendo uma das mais importantes tecnologias agrícolas disponível para a mitigação das mudanças climáticas globais (FAO, 2006). Na Bacia Hidrográfica do Rio Paranaíba as pastagens ocupam $41.1 \%$ da área da bacia, das quais aproximadamente $50 \%$ apresentam algum grau de degradação. As perdas de carbono em pastagens podem ser mínimas ou até mesmo armazenar mais carbono em comparação com a vegetação natural, quando bem manejadas.

Face ao exposto, neste trabalho buscam-se referências no sentido de se determinar o carbono orgânico total do solo (COT), sob pastagens melhoradas e degradadas, com o intuído de verificar se pastagens bem manejadas são mais eficientes no armazenamento de carbono da atmosfera.

A FAO (2006) define o carbono no solo como o carbono orgânico presente nos solos minerais e orgânicos numa profundidade de até $30 \mathrm{~cm}$. Entretanto, é pertinente salientar que os solos são ecossistemas frágeis e o mau uso pode aumentar a taxa de mineralização e transferir carbono para atmosfera. Em geral, a conversão de ecossistemas naturais em ecossistemas agrícolas leva à diminuição do estoque de carbono no solo, em conseqüência do uso inapropriado de práticas de manejos.

Em linhas gerais, os solos arenosos apresentam maior proporção da matéria orgânica associadas a partículas de areia, o que lhes confere maior fragilidade perante as mudanças nos sistemas de manejo, quando comparado com solos argilosos, uma vez que fração composta por resíduos vegetais é facilmente mineralizada (FREIXO, et. al., 2002).

\section{ABORDAGEM METODOLÓGICA}

\section{Amostragem do Solo}

Para a estimativa da quantidade de carbono estocado nos solos sob pastagens cultivadas, foram coletadas 80 amostras de solo, de forma aleatória (Figura 02), sendo 40 em pastagens degradadas e 40 em pastagens melhoradas, nas profundidades de $0-5$ $\mathrm{cm} ; 5-10 \mathrm{~cm} ; 10-20 \mathrm{~cm}$ e $20-30 \mathrm{~cm}$, totalizando 320 amostras para análise ( 80 pontos amostrais vezes quatro profundidades). As amostras foram coletadas durante os meses de fevereiro, março, abril e maio de 2012 e a localização de cada ponto foi determinada com GPS. 
Figura 2. Localização das amostras onde foi coletado o solo

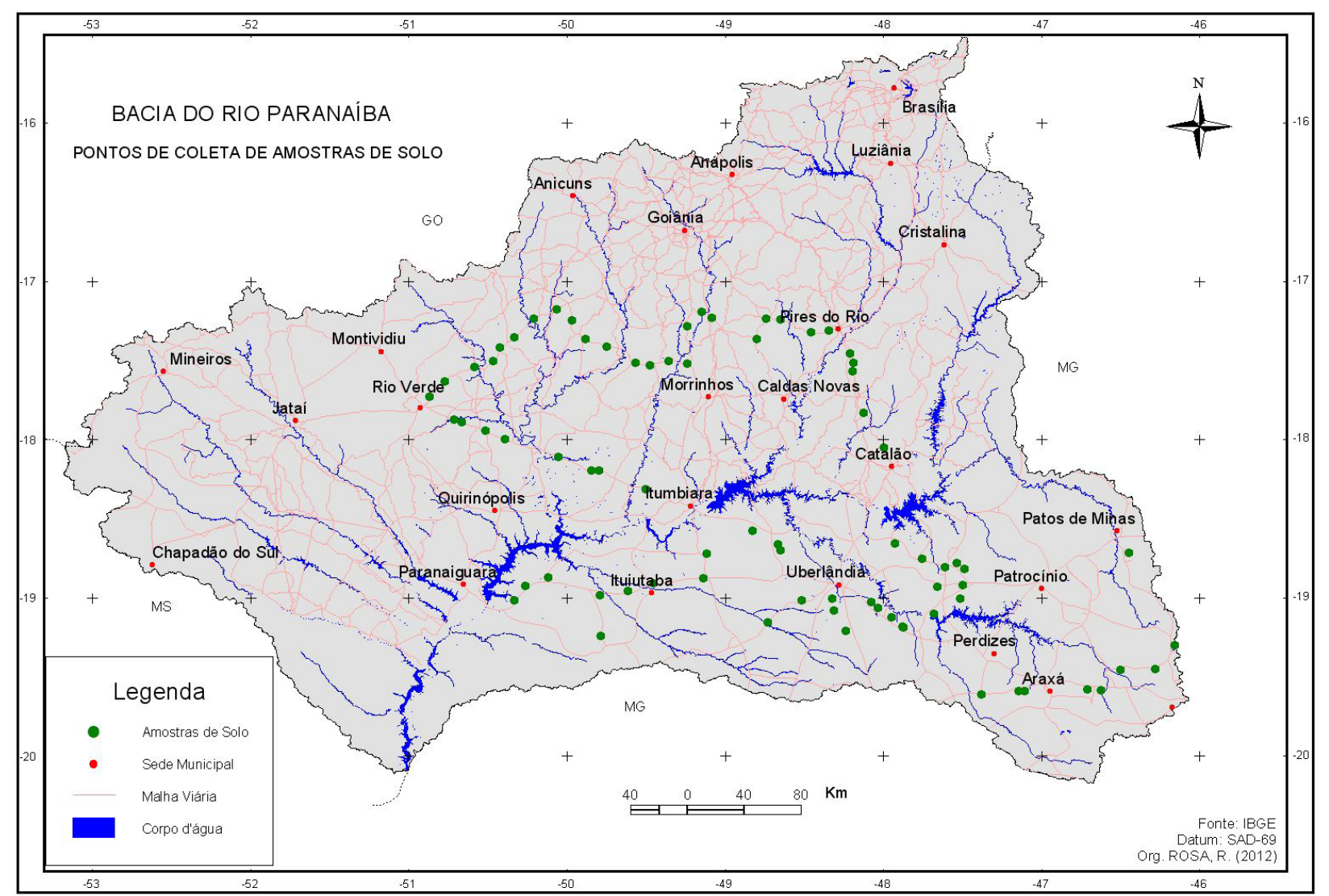

Org. dos autores.

Após coletadas, as amostras foram armazenadas em sacos plásticos para posterior secagem ao ar e peneiramento com malha de $2 \mathrm{~mm}$ de abertura (terra fina seca ao ar - TFSA). Parte do solo foi separado para análise do carbono e parte foi usado para análise granulométrica.

As variáveis do solo estudadas foram: areia, silte, argila (\%), densidade $\left(\mathrm{g} / \mathrm{cm}^{3}\right)$, teor de carbono total $(\%)$ e estoque de carbono $(\mathrm{Mg} / \mathrm{ha})$.

\section{Densidade Aparente}

A densidade do solo foi determinada pelo método do anel volumétrico, conforme Embrapa (1997). O volume do anel foi determinado conforme a equação a seguir:

$$
\mathrm{V}=\pi \mathrm{d}^{2} / 4 . h
$$

Onde: $\mathrm{V}$ é volume do anel $\left(\mathrm{cm}^{3}\right)$, d é diâmetro do anel $(\mathrm{cm})$, h é a altura do anel $(\mathrm{cm})$
Para análise da densidade foram realizadas três repetições para cada profundidade de coleta $0-5 \mathrm{~cm} ; 5$ $-10 \mathrm{~cm} ; 10-20 \mathrm{~cm}$ e $20-30 \mathrm{~cm}$, totalizando 12 coletas em cada ponto amostral, totalizando 960 amostras para análise da densidade. Os anéis foram cravados no solo, por meio de percussão, até seu preenchimento total. Posteriormente, removeu-se o excesso de solo, até igualar as bordas do anel. As amostras foram retiradas na porção média da camada. O solo obtido dentro do anel foi transferido para um recipiente e levado para secar em uma estufa a $105^{\circ} \mathrm{C}$, por 48 horas, visando obter sua massa. Após esse período, determinou-se a densidade através da equação:

$$
\mathrm{D}=\mathrm{m} / \mathrm{v}
$$

Onde: D é a densidade aparente do solo $(\mathrm{g} /$ $\left.\mathrm{cm}^{3}\right)$, $\mathrm{m}$ é a massa de solo seco ( $\mathrm{g}$ ), e v é o volume do anel $\left(\mathrm{cm}^{3}\right)$.

As análises de densidade foram realizadas no Laboratório de Geomorfologia e Erosão do Solo do IG/UFU. 


\section{Análise Granulométrica}

A análise granulométrica foi realizada segundo os procedimentos descritos no Manual de Métodos de Análise de Solo (EMBRAPA, 1997), no Laboratório de Análise e Manejo do Solo do ICIAG/UFU.

\section{Teor de Carbono no Solo}

De acordo com Nelson e Sommers (1996), o carbono orgânico pode ser obtido por: (a) análise do carbono total do solo e do carbono inorgânico e posterior subtração dessa fração da total; (b) determinação do C total após remoção do C inorgânico; e (c) oxidação do $\mathrm{CO}$ por dicromato e subsequente determinação do dicromato não reduzido pela titulação de oxirredução com $\mathrm{Fe}^{2+}$, ou por métodos colorimétricos.

Vários equipamentos automatizados que determinam, simultaneamente, $\mathrm{C}, \mathrm{H}$ e $\mathrm{N}$ têm sido desenvolvidos, apesar do elevado custo inicial, eles possibilitam que maior número de amostras seja analisado em menor tempo, com o mínimo de variabilidade entre elas. Existem, portanto, vários métodos para se determinar o carbono em amostras de solo. O método da combustão a seco é considerado padrão, devido a sua alta precisão e exatidão nos resultados ( $\mathrm{SOON}$ e ABBOUD, 1991; NELSON e SOMMERS, 1996).

Na presente pesquisa o teor de carbono total foi determinado pelo método da combustão a seco utilizando um Analisador Elementar (CHNS-O) Flash2000, da Thermo Scientific pertencente ao Laboratório de Química da FACIP/UFU.

Amostras de $1.0 \mathrm{~g}$ de solo seco ao ar (TFSA) foram trituradas em almofariz de ágata, em seguida, foram transferidas individualmente para um pequeno tubo e acondicionadas em um dessecador, levadas para secar em estufa a aproximadamente $60^{\circ}$ durante 24 horas, para retirar possível umidade existente, antes de se proceder à análise via combustão seca (CHNS-O) em Analisador Elementar Flash2000.

Cada amostra de solo $(1 \mathrm{mg})$ depois de pesada em cápsulas de estanho é acondicionada em um autosampler e queimada por um reator a $900{ }^{\circ} \mathrm{C}$. Cada amostra de solo foi pesada em triplicata para as profundidades de $0-5 ; 5-10 ; 10-20$ e $20-30 \mathrm{~cm}$.

\section{Estoque de Carbono no Solo}

Após as análises de laboratório da densidade (D) e teor de carbono (C) as amostras coletadas em campo sob pastagens (nas profundidades $0-5 \mathrm{~cm}, 5$ $-10 \mathrm{~cm}, 10-20 \mathrm{~cm}$ e $20-30 \mathrm{~cm}$ ), foram submetidas à mensuração do estoque de carbono. $\mathrm{O}$ estoque de carbono $(\mathrm{Mg} / \mathrm{ha})$ foi calculado por meio da multiplicação do conteúdo do carbono (\%), da densidade do solo $\left(\mathrm{g} / \mathrm{cm}^{3}\right)$ e da espessura da camada de solo $(\mathrm{cm})$, conforme equação a seguir:

$$
\mathrm{EstC}=\mathrm{C} * \mathrm{D} * \mathrm{E}
$$

Onde EstC é o estoque de carbono na camada analisada (Mg/ha), C é o teor de carbono total (\%), D é a densidade aparente do solo da camada analisada $\left(\mathrm{g} / \mathrm{cm}^{3}\right)$ e, E é a espessura da camada $(\mathrm{cm})$.

\section{RESULTADOS E DISCUSÃO}

A partir da análise das Tabelas 01 e 02, observa-se que globalmente, tanto para PM quanto para a PD o percentual médio de areia grossa, areia fina, silte e argila é pouco variável nas diferentes camadas de solo, com pequeno decréscimo da areia grossa e aumento da argila à medida que a profundidade aumenta.

Tabela 01. Caracterização granulométrica dos solos sob pastagem melhorada

\begin{tabular}{|l|r|r|r|r|r|r|r|r|}
\hline \multirow{2}{*}{ Camada (cm) } & \multicolumn{2}{|c|}{ Areia Grossa } & \multicolumn{2}{c|}{ Areia Fina } & \multicolumn{2}{c|}{ Silte } & \multicolumn{2}{c|}{ Argila } \\
\cline { 2 - 9 } & Média & \multicolumn{1}{c|}{ DP } & Média & \multicolumn{1}{c|}{ DP } & Média & \multicolumn{1}{c|}{ DP } & Média & \multicolumn{1}{l|}{ DP } \\
\hline $\mathbf{0}-\mathbf{5}$ & 20.3 & 10.6 & 23.7 & 14.7 & 17.5 & 13.1 & 38.5 & 15.0 \\
\hline $\mathbf{5}-\mathbf{1 0}$ & 19.5 & 10.2 & 24.1 & 15.7 & 17.8 & 13.6 & 38.6 & 15.6 \\
\hline $\mathbf{1 0}-\mathbf{2 0}$ & 18.8 & 10.5 & 23.5 & 14.6 & 17.2 & 12.8 & 40.5 & 16.2 \\
\hline $\mathbf{2 0}-\mathbf{3 0}$ & 18.8 & 10.3 & 23.3 & 15.0 & 17.3 & 12.9 & 40.6 & 15.8 \\
\hline
\end{tabular}

$\mathrm{DP}=$ Desvio Padrão

Org. dos autores. 
Observa-se que em média à pastagem melhorada ocupa solos com aproximadamente $40 \%$ de argila, $23 \%$ de areia fina, $19 \%$ de areia grossa e $18 \%$ de silte, independente da camada analisada. O mesmo acontece com a pastagem degradada que ocupa áreas com solo que possui em média $41 \%$ de argila, $25 \%$ de areia fina, $21 \%$ de areia grossa e $13 \%$ de silte. Em médias, a textura dos solos sob pastagem melhorada e degradada são muito semelhantes, no entanto, convém destacar que as amostras possuem um desvio padrão elevado, o que caracteriza a heterogeneidade dos solos ocupados com pastagens.

Tabela 02. Caracterização granulométrica dos solos sob pastagem degradada

\begin{tabular}{|l|r|r|r|r|r|r|r|r|}
\hline \multirow{2}{*}{ Camada (cm) } & \multicolumn{2}{|c|}{ Areia Grossa } & \multicolumn{2}{c|}{ Areia Fina } & \multicolumn{2}{c|}{ Silte } & \multicolumn{2}{c|}{ Argila } \\
\cline { 2 - 9 } & Média & DP & Média & DP & Média & DP & Mé dia & \multicolumn{1}{l|}{ DP } \\
\hline $\mathbf{0 - 5}$ & 21.5 & 12.3 & 25.2 & 15.2 & 13.2 & 12.1 & 40.0 & 16.9 \\
\hline $\mathbf{5}-\mathbf{1 0}$ & 21.1 & 13.0 & 25.2 & 15.5 & 12.9 & 12.2 & 40.9 & 16.3 \\
\hline $\mathbf{1 0}-\mathbf{2 0}$ & 20.1 & 11.4 & 25.2 & 15.4 & 13.1 & 11.0 & 41.6 & 15.9 \\
\hline $\mathbf{2 0}-\mathbf{3 0}$ & 19.9 & 12.1 & 24.6 & 15.3 & 13.2 & 11.2 & 42.4 & 16.8 \\
\hline
\end{tabular}

Org. dos autores.

Na Tabela 03 e Figura 03, é apresentado o número de amostras de solo em cada classe de textura. Observa-se que para pastagem melhorada o maior número de amostras foram coletadas em solos com textura argilosa (40\% das amostras) e textura média
(20\%), enquanto que o menor número foi coletado em solos com textura argilo siltosa (5\%). Já para a pastagem degradada, o maior número de amostras foi coletado sobre solo com textura arenosa $(27 \%)$, seguido pelos solos de textura argilosa $(25 \%)$.

Tabela 03. Quantidade de amostras segundo as classes de textura do solo

\begin{tabular}{|l|r|r|r|r|}
\hline \multirow{2}{*}{ Textura } & \multicolumn{2}{|c|}{ Pastagem Melhora da } & \multicolumn{2}{c|}{ Pastagem Degradada } \\
\cline { 2 - 5 } & No. Amostras & $\mathbf{\%}$ & No. Amostras & $\mathbf{\%}$ \\
\hline Arenosa & 5 & 12.5 & 11 & 27.5 \\
\hline Média & 2 & 20.0 & 5 & 12.5 \\
\hline Argilo Arenosa & 7 & 17.5 & 2 & 5.0 \\
\hline Argilo Siltosa & 2 & 5.0 & 6 & 15 \\
\hline Argilosa & 16 & 40.0 & 10 & 25.0 \\
\hline Muito Argilosa & 2 & 5.0 & 6 & 15.0 \\
\hline & 40 & 100.0 & 40 & 100.00 \\
\hline
\end{tabular}

Org. dos autores. 
Quando se agrupa as classes de textura areia grossa+areia fina e argila+silte, observa-se que em média as pastagens (melhorada e degradada), ocupam áreas de solo com características físicas similares.

Figura 03. Percentual de amostras de solo segundo as classes de textura

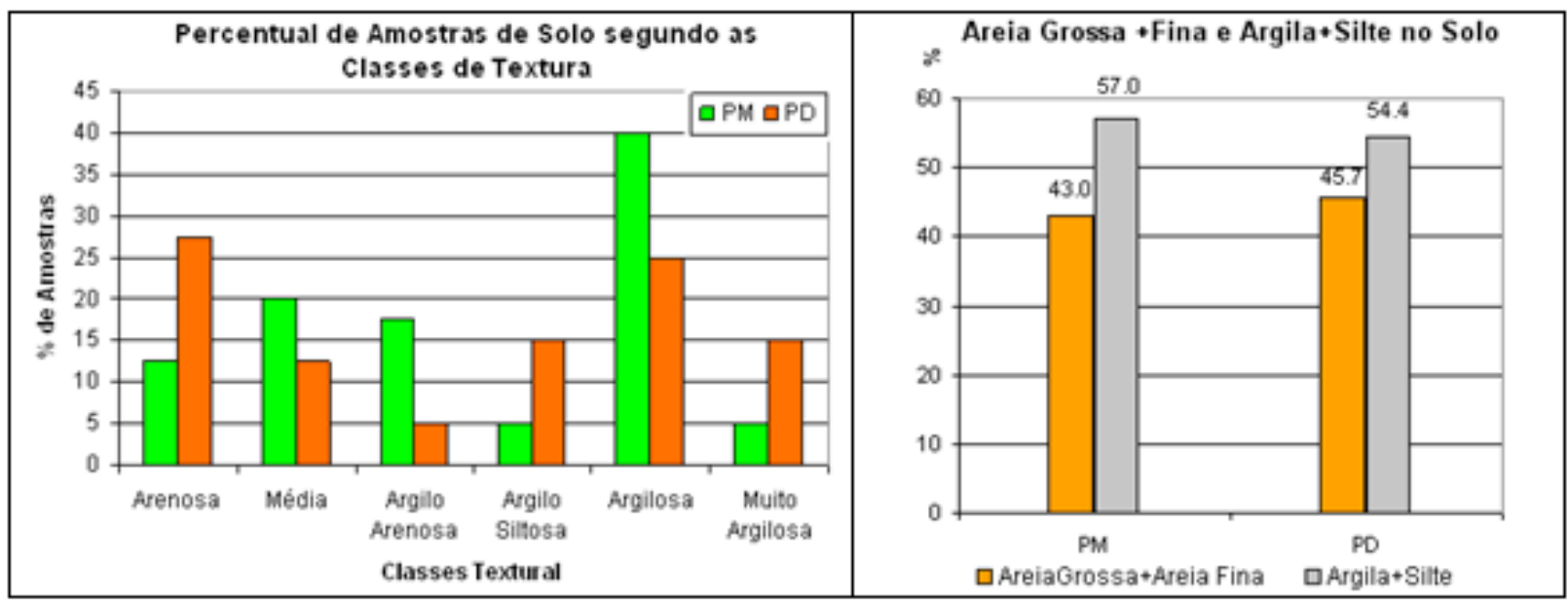

Org. dos autores.

As Tabelas 04, 05, 06 e 07, mostram de forma condensada, a média, desvio padrão, coeficiente de variação, valor máximo e mínino das características do solo sob pastagem melhorada e degradada nas diferentes profundidades. Cabe destacar que, em média, os valores de qualquer característica física, variam muito pouco entre as diferentes profundidades de análise, no entanto o coeficiente de variação entre as amostras de uma determinada camada é elevado. Os valores, máximo e mínimo foram utilizados para verificar possíveis valores atípicos.

Tabela 04. Caracterização dos solos sob pastagem (camada $0-5 \mathrm{~cm}$ )

\begin{tabular}{|l|r|r|r|r|r|r|r|r|r|r|}
\hline & \multicolumn{4}{|c|}{ Pastage m Melhorada } & \multicolumn{4}{|c|}{ Pastagem Degradada } \\
\hline & Média & \multicolumn{1}{|c|}{ DP } & \multicolumn{1}{|c|}{ CV } & \multicolumn{1}{|c|}{ Máx. } & Mín. & Mé dia & \multicolumn{1}{c|}{ DP } & \multicolumn{1}{c|}{ CV } & Máx. & Mín. \\
\hline Areia Grossa (\%) & 20.3 & 10.6 & 52.4 & 38.4 & 1.7 & 21.5 & 12.3 & 57.4 & 57.1 & 2.4 \\
\hline Areia Fina (\%) & 23.7 & 14.7 & 62.2 & 51.9 & 1.0 & 25.2 & 15.2 & 60.0 & 56.5 & 1.4 \\
\hline Silte (\%) & 17.5 & 13.1 & 74.5 & 50.5 & 1.2 & 13.2 & 12.1 & 91.4 & 50.6 & 1.3 \\
\hline Argila (\%) & 38.5 & 15.0 & 39.1 & 72.6 & 7.9 & 40.0 & 16.9 & 42.1 & 77.2 & 6.5 \\
\hline Umidade (\%) & 26.7 & 7.4 & 27.7 & 42.1 & 13.7 & 19.7 & 10.1 & 51.2 & 38.5 & 1.5 \\
\hline Densidade (g/cm) & 1.16 & 0.15 & 13.3 & 1.60 & 0.89 & 1.26 & 0.18 & 14.0 & 1.58 & 0.96 \\
\hline Teor de C (\%) & 2.60 & 0.70 & 26.9 & 4.46 & 1.58 & 1.90 & 0.58 & 30.7 & 3.51 & 0.80 \\
\hline Es toque C (Mg/ha) & 14.76 & 3.1 & 21.1 & 24.44 & 9.44 & 11.62 & 2.5 & 21.2 & 16.87 & 6.23 \\
\hline
\end{tabular}

DP é o desvio padrão, CV é o coeficiente de variação (\%), Máx. é o valor máximo, Mín. é o valor mínimo.

Org. dos autores. 
Tabela 05. Caracterização dos solos sob pastagem (camada $5-10 \mathrm{~cm}$ )

\begin{tabular}{|l|r|r|r|r|r|r|r|r|r|r|}
\hline & \multicolumn{4}{|c|}{ Pastage m Melhorada } & \multicolumn{4}{|c|}{ Pastagem Degradada } \\
\hline & Média & \multicolumn{1}{|c|}{ DP } & \multicolumn{1}{|c|}{ CV } & Máx. & Mín. & Mé dia & \multicolumn{1}{c|}{ DP } & \multicolumn{1}{c|}{ CV } & Máx. & Mín. \\
\hline Areia Grossa (\%) & 19.5 & 10.2 & 52.2 & 36.1 & 1.0 & 21.1 & 13.0 & 61.7 & 64.5 & 2.2 \\
\hline Areia Fina (\%) & 24.1 & 15.7 & 65.1 & 56.9 & 1.0 & 25.2 & 15.5 & 61.6 & 58.7 & 1.6 \\
\hline Silte (\%) & 17.8 & 13.6 & 76.4 & 56.1 & 1.6 & 12.9 & 12.2 & 94.8 & 50.0 & 1.4 \\
\hline Argila (\%) & 38.6 & 15.6 & 40.4 & 76.0 & 7.7 & 40.9 & 16.3 & 39.9 & 76.2 & 6.0 \\
\hline Umidade (\%) & 24.6 & 6.9 & 27.9 & 37.5 & 13.4 & 19.5 & 8.8 & 45.1 & 35.8 & 3.8 \\
\hline Densidade (g/cm $\mathbf{3})$ & 1.22 & 0.14 & 11.14 & 1.54 & 1.01 & 1.29 & 0.18 & 13.91 & 1.60 & 0.95 \\
\hline Teor de C (\%) & 2.18 & 0.63 & 28.8 & 4.15 & 1.24 & 1.75 & 0.52 & 29.6 & 3.12 & 0.93 \\
\hline Estoque C (Mg/ha) & 13.05 & 3.3 & 25.5 & 24.10 & 7.75 & 10.99 & 2.4 & 22.1 & 16.31 & 6.85 \\
\hline
\end{tabular}

DP é o desvio padrão, CV é o coeficiente de variação (\%), Máx é o valor máximo, Mín. é o valor mínimo.

Org. dos autores.

Tabela 06. Caracterização dos solos sob pastagem (camada 10 - $20 \mathrm{~cm}$ )

\begin{tabular}{|l|r|r|r|r|r|r|r|r|r|r|}
\hline & \multicolumn{4}{|c|}{ Pastage m Melhorada } & \multicolumn{4}{c|}{ Pastagem Degradada } \\
\cline { 2 - 11 } & Média & \multicolumn{1}{|c|}{ DP } & \multicolumn{1}{|c|}{ CV } & Máx. & Mín. & Média & \multicolumn{1}{c|}{ DP } & \multicolumn{1}{c|}{ CV } & Máx. & Mín. \\
\hline Areia Grossa (\%) & 18.8 & 10.5 & 55.8 & 37.8 & 2.2 & 20.1 & 11.4 & 57.0 & 59.6 & 2.5 \\
\hline Areia Fina (\%) & 23.5 & 14.6 & 62.3 & 54.6 & 1.2 & 25.2 & 15.4 & 61.2 & 61.5 & 1.5 \\
\hline Silte (\%) & 17.2 & 12.8 & 74.6 & 54.0 & 1.4 & 13.1 & 11.0 & 83.5 & 41.5 & 0.7 \\
\hline Argila (\%) & 40.5 & 16.2 & 40.0 & 79.0 & 8.2 & 41.6 & 15.9 & 38.3 & 66.7 & 7.4 \\
\hline Umidade (\%) & 24.9 & 7.4 & 29.9 & 41.7 & 9.6 & 19.7 & 9.0 & 45.8 & 35.4 & 4.3 \\
\hline Densidade (g/cm $\mathbf{3}$ ) & 1.24 & 0.14 & 11.35 & 1.56 & 1.02 & 1.29 & 0.17 & 13.56 & 1.58 & 1.00 \\
\hline Teor de C (\%) & 1.76 & 0.49 & 27.8 & 3.10 & 0.84 & 1.56 & 0.56 & 36.0 & 2.82 & 0.66 \\
\hline Estoque C (Mg/ha) & 21.29 & 4.6 & 21.7 & 31.67 & 12.31 & 19.57 & 5.6 & 28.4 & 29.34 & 7.49 \\
\hline
\end{tabular}

DP é o desvio padrão, CV é o coeficiente de variação (\%), Máx. é o valor máximo, Mín. é o valor mínimo.

Org. dos autores.

Tabela 07. Caracterização dos solos sob pastagem (camada $20-30 \mathrm{~cm}$ )

\begin{tabular}{|l|r|r|r|r|r|r|r|r|r|r|}
\hline & \multicolumn{4}{|c|}{ Pastage m Melhorada } & \multicolumn{4}{c|}{ Pastage m Degradada } \\
\hline & Mé dia & \multicolumn{1}{|c|}{ DP } & \multicolumn{1}{|c|}{ CV } & \multicolumn{1}{|c|}{ Máx. } & Min. & Média & \multicolumn{1}{c|}{ DP } & CV & Máx. & Mín. \\
\hline Areia Grossa (\%) & 18.8 & 10.3 & 54.8 & 39.4 & 1.5 & 19.9 & 12.1 & 60.8 & 57.3 & 2.2 \\
\hline Arria Fina (\%) & 23.3 & 15.0 & 64.4 & 61.5 & 1.1 & 24.6 & 15.3 & 62.3 & 60.3 & 1.4 \\
\hline Silte (\%) & 17.3 & 12.9 & 74.7 & 53.8 & 1.9 & 13.2 & 11.2 & 84.8 & 47.0 & 0.8 \\
\hline Argila (\%) & 40.6 & 15.8 & 39.0 & 76.9 & 8.9 & 42.4 & 16.8 & 39.6 & 75.3 & 8.2 \\
\hline Umidade (\%) & 24.0 & 7.1 & 29.6 & 38.0 & 9.9 & 19.6 & 8.7 & 44.5 & 34.2 & 4.6 \\
\hline Densidade (g/cm) & 1.24 & 0.14 & 11.28 & 1.51 & 1.00 & 1.30 & 0.18 & 13.84 & 1.67 & 1.00 \\
\hline Teor de C (\%) & 1.58 & 0.45 & 28.8 & 3.01 & 0.90 & 1.36 & 0.54 & 40.1 & 2.64 & 0.32 \\
\hline Es toque C (Mg/ha) & 19.18 & 4.3 & 22.6 & 30.27 & 12.71 & 17.17 & 5.7 & 33.1 & 27.43 & 4.10 \\
\hline
\end{tabular}

DP é o desvio padrão, CV é o coeficiente de variação (\%), Máx. é o valor máximo, Mín. é o valor mínimo.

Org. dos autores. 
A partir da análise das Tabelas 04 a 07, observa-se que o teor de carbono diminui com a profundidade do solo, independente da pastagem ser melhorada ou degradada. Verifica-se que em média, a pastagem melhorada apresenta um valor mais elevado de carbono no solo do que a pastagem degradada, em todas as profundidades analisadas.

Na camada $0-5 \mathrm{~cm}$ de profundidade a pastagem melhorada apresenta um teor de carbono em média de $2.60 \%$ enquanto que a pastagem degradada o teor de carbono é de $1.90 \%$. Na camada $5-10 \mathrm{~cm}$, a pastagem melhorada possui teor de carbono de $2.18 \%$ e a degradada de $1.75 \%$. Na camada $10-20 \mathrm{~cm}$, o teor de carbono da pastagem melhorada é de 1.76\%, já a pastagem degradada possui $1.56 \%$. Na camada de maior profundidade $(20-30 \mathrm{~cm})$, a pastagem melhorada apresenta $1.58 \%$ de teor de carbono, enquanto que a degradada possui $1.36 \%$. O coeficiente de variação entre os teores de carbono das 40 amostras situa-se em torno de $30 \%$, tanto para a pastagem melhorada quanto para pastagem degradada.

Na Tabela 08 e Figura 04 apresentamos uma síntese das características dos solos sob pastagem para as diferentes profundidades. Observamos que em média a umidade do solo decresce com o aumento da profundidade para a pastagem melhorada, passando de $26.7 \%$ de umidade na camada 0 - 5 cm para $24.0 \%$ para a camada de $20-30 \mathrm{~cm}$. Já na pastagem degradada à umidade varia muito pouco com a profundidade, ficando em torno de $19 \%$. Observa-se também que os solos sob pastagem melhorada apresentam em média $5 \%$ a mais de umidade quando comparados com os solos obtidos sob pastagem degradada.

Tabela 08. Síntese das características dos solos sob pastagem nas diferentes profundidades $(\mathrm{cm})$

\begin{tabular}{|l|r|r|r|r|r|r|r|r|}
\hline & \multicolumn{4}{|c|}{ Pastage m Melhorada } & \multicolumn{3}{|c|}{ Pastage m Degradada } \\
\cline { 2 - 8 } Caracteristicas & $\mathbf{0 - 5}$ & $\mathbf{5}-\mathbf{1 0}$ & $\mathbf{1 0 - 2 0}$ & $\mathbf{2 0 - 3 0}$ & $\mathbf{0 - 5}$ & $\mathbf{5}-\mathbf{1 0}$ & $\mathbf{1 0 - 2 0}$ & $\mathbf{2 0}-\mathbf{3 0}$ \\
\hline Areia Grossa (\%) & 20.3 & 19.5 & 18.8 & 18.8 & 21.5 & 21.1 & 20.1 & 19.9 \\
\hline Areia Fina (\%) & 23.7 & 24.1 & 23.5 & 23.3 & 25.2 & 25.2 & 25.2 & 24.6 \\
\hline Silte (\%) & 17.5 & 17.8 & 17.2 & 17.3 & 13.2 & 12.9 & 13.1 & 13.2 \\
\hline Argila (\%) & 38.5 & 38.6 & 40.5 & 40.6 & 40.0 & 40.9 & 41.6 & 42.4 \\
\hline Umidade (\%) & 26.7 & 24.6 & 24.9 & 24.0 & 19.7 & 19.5 & 19.7 & 19.6 \\
\hline Densidade (g/cm) & 1.16 & 1.22 & 1.24 & 1.24 & 1.26 & 1.29 & 1.29 & 1.30 \\
\hline Teor de C (\%) & 2.60 & 2.18 & 1.76 & 1.58 & 1.90 & 1.75 & 1.56 & 1.36 \\
\hline Es toque C (Mg/ha) & 14.76 & 13.05 & 21.29 & 19.18 & 11.62 & 10.99 & 19.57 & 17.17 \\
\hline
\end{tabular}

Org. dos autores.

A densidade do solo sob pastagem melhorada é menor do que a dos solos sob pastagem degradada, demonstrando que uma pastagem bem manejada, permite um solo mais estruturado, com maior porosidade, o que favores a infiltração de água da chuva, diminuindo o escoamento superficial. Observa-se também que a densidade aumenta com o aumento da profundidade de coleta do solo, em ambos os tipos de pastagem.

A partir da análise da Tabela 08 observa-se que em média, o percentual de areia grossa diminui com o aumento da profundidade do solo e o percentual de argila aumenta, embora de forma bastante discreta.

A Tabela 09 mostra uma síntese do teor de carbono (\%) para a pastagem melhorada e degradada nas diferentes profundidades de coleta de solo e na Tabela 10 são apresentados os resultados do estoque de carbono (Figura 05).

Observa-se que a camada superficial $(0-5$ $\mathrm{cm})$ apresenta o maior teor de carbono, tanto para pastagem melhorada quanto para pastagem degradada. Tendo como valor máximo uma amostra com teor de carbono de $4.46 \%$ e uma amostra com o valor mínimo de $1.58 \%$. Observa-se na Figura 05 que a pastagem melhorada possui em média um valor maior de teor de carbono no solo em todas as profundidades. Também observa-se, que com o aumento da profundidade o teor de carbono decresce. 
Estoque de carbono em solos sob pastagens cultivadas na bacia hidrográfica do Rio Paranaíba

Roberto Rosa, Edson Eyji Sano, Jussara dos Santos Rosendo

Figura 04. Umidade e densidade do solo sob pastagem nas diferentes profundidades

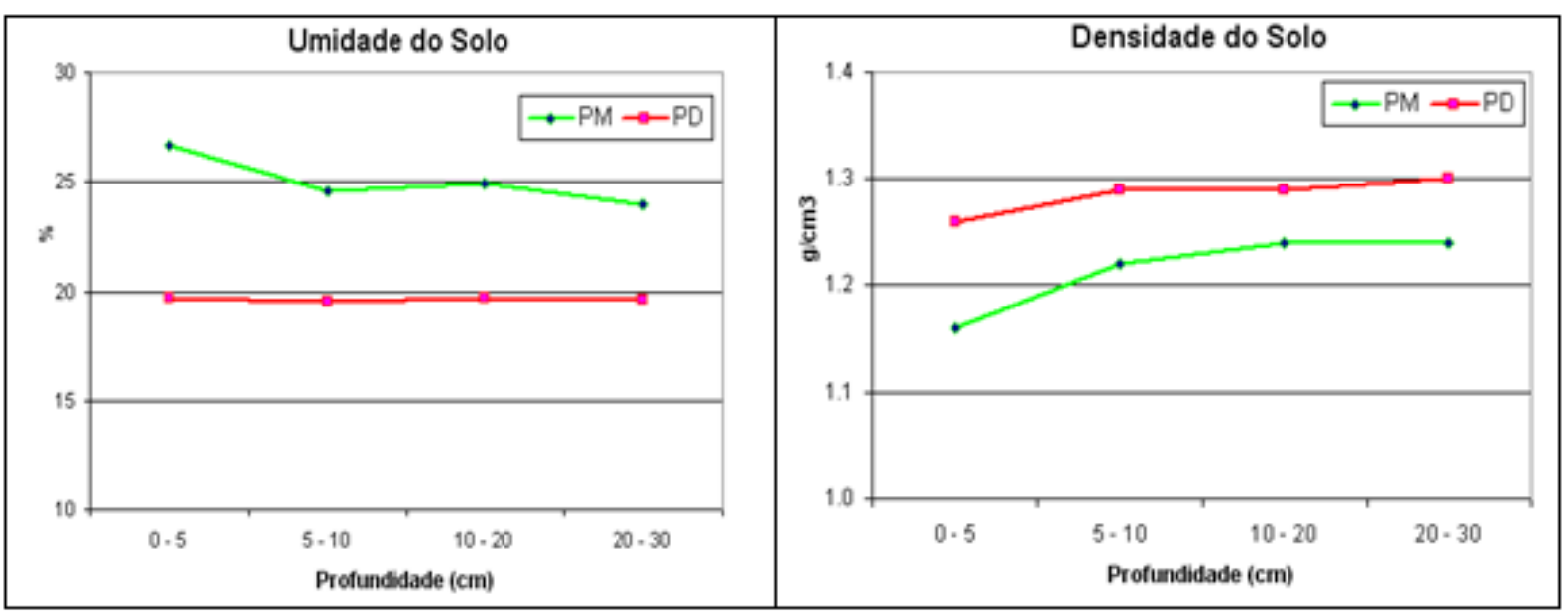

Org. dos autores.

Tabela 09. Síntese do teor de carbono (\%) das amostras de solo nas diferentes profundidades (Pastagem Melhorada e Degradada)

\begin{tabular}{|l|r|r|r|r|r|r|r|r|r|r|}
\hline \multirow{2}{*}{ Camada (cm) } & \multicolumn{4}{|c|}{ Pastage m Melhorada } & \multicolumn{4}{c|}{ Pastage m Degradada } \\
\cline { 2 - 10 } & Teor C & DP & CV & Máx. & Mín. & Teor C & DP & CV & Máx. & Mín. \\
\hline $0-5$ & 2.60 & 0.70 & 26.9 & 4.46 & 1.58 & 1.90 & 0.58 & 30.7 & 3.51 & 0.80 \\
\hline $5-10$ & 2.18 & 0.63 & 28.8 & 4.15 & 1.24 & 1.75 & 0.52 & 29.6 & 3.12 & 0.93 \\
\hline $10-20$ & 1.76 & 0.49 & 27.8 & 3.10 & 0.84 & 1.56 & 0.56 & 36.0 & 2.82 & 0.66 \\
\hline $20-30$ & 1.58 & 0.45 & 28.8 & 3.01 & 0.90 & 1.36 & 0.54 & 40.1 & 2.64 & 0.32 \\
\hline
\end{tabular}

DP é o desvio padrão, CV é o coeficiente de variação (\%), Máx é o valor máximo, Mín. é o valor mínimo.

Org. dos autores.

Figura 05. Teor de carbono (\%) e estoque de carbono (MG/ha) para pastagem melhorada (PM) e pastagem degradada (PD)

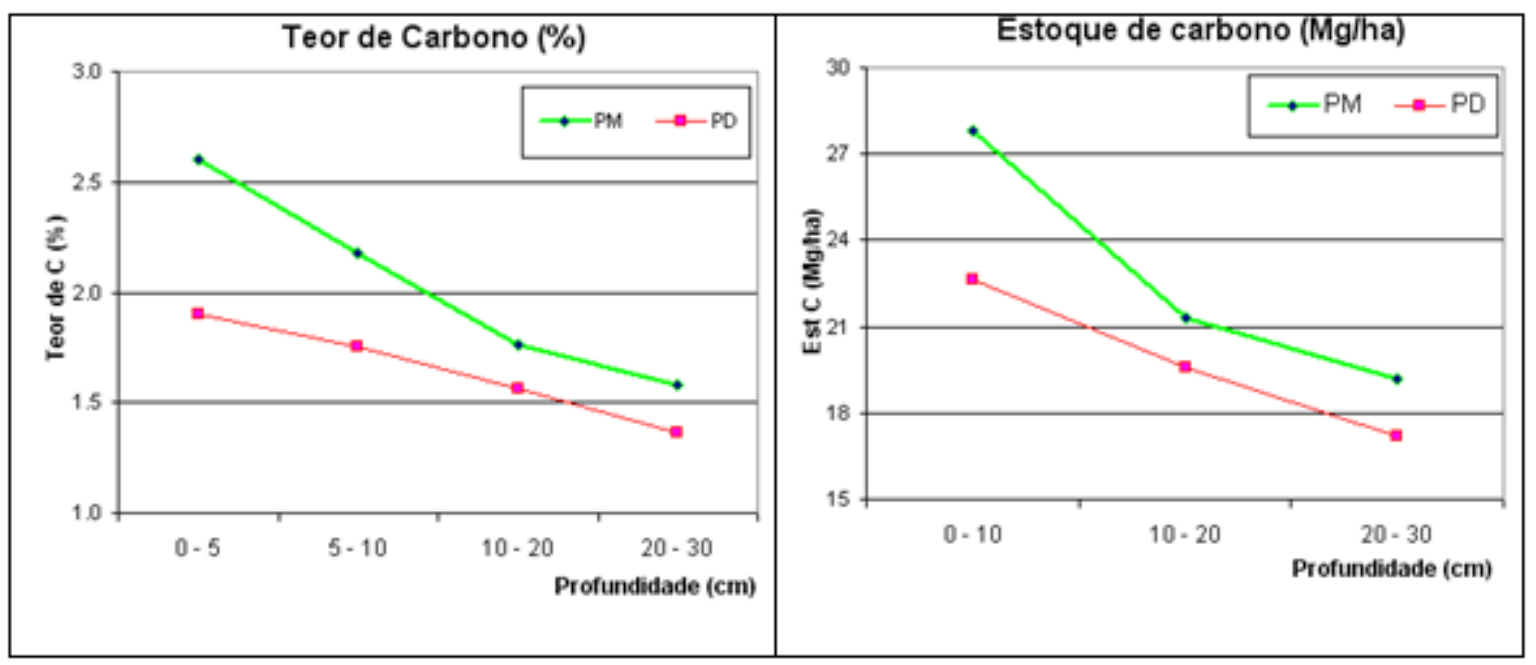

Org. dos autores.

Soc. \& Nat., Uberlândia, 26 (2): 333-351, mai/ago/2014 
Baseado no teor de carbono, na densidade e na espessura da camada de solo onde foi coletada a amostra, foi possível quantificar o estoque de carbono na referida camada em $\mathrm{Mg} / \mathrm{ha}$. A partir da análise da Tabela 10 verifica-se que o valor do estoque de carbono na profundidade de $0-10 \mathrm{~cm}$ (soma da duas primeiras camadas) é de $27.81 \mathrm{Mg}$ /ha para a pastagem melhorada e de 22.61 $\mathrm{Mg} / \mathrm{ha}$, para a pastagem degradada, decrescendo nas outras camadas, sendo que sempre a pastagem melhorada apresenta um valor maior de estoque de carbono.
Convém destacar que se considerarmos toda a camada (0 - $30 \mathrm{~cm}$ de profundidade) observa-se que a pastagem melhorada possui em média um estoque de carbono de $68.28 \mathrm{Mg} /$ ha enquanto que a pastagem degradada apresenta estoque de $59.35 \mathrm{Mg} /$ ha. Portanto, a pastagem melhorada apresenta um estoque de carbono no solo $15 \%$ maior do que a pastagem degradada.

Quando se considera apenas a camada mais superficial $(0-10 \mathrm{~cm})$ esta diferença chega a ser de aproximadamente $23 \%$ maior para pastagem melhorada.

Tabela 10. Estoque de carbono ( $\mathrm{Mg} / \mathrm{ha})$ nas diferentes camadas de solo (Pastagem Melhorada e Degradada)

\begin{tabular}{|l|r|r|r|r|r|r|r|r|r|r|}
\hline \multirow{2}{*}{ Camada (cm) } & \multicolumn{4}{|c|}{ Pastage m Melhorada } & \multicolumn{4}{c|}{ Pastagem Degradada } \\
\cline { 2 - 11 } & Est C & \multicolumn{1}{c|}{ DP } & \multicolumn{1}{c|}{ CV } & Máx. & Min. & Est C & \multicolumn{1}{c|}{ DP } & \multicolumn{1}{c|}{ CV } & Máx. & Mín. \\
\hline $0-5$ & 14.76 & 3.1 & 21.1 & 24.44 & 9.44 & 11.62 & 2.5 & 21.2 & 16.87 & 6.23 \\
\hline $5-10$ & 13.05 & 3.3 & 25.5 & 24.10 & 7.75 & 10.99 & 2.4 & 22.1 & 16.31 & 6.85 \\
\hline $10-20$ & 21.29 & 4.6 & 21.7 & 31.67 & 12.31 & 19.57 & 5.6 & 28.4 & 29.34 & 7.49 \\
\hline $20-30$ & 19.18 & 4.3 & 22.6 & 30.27 & 12.71 & 17.17 & 5.7 & 33.1 & 27.43 & 4.10 \\
\hline Total (0-30) & $\mathbf{6 8 . 2 8}$ & - & - & - & - & $\mathbf{5 9 . 3 5}$ & - & - & - & - \\
\hline
\end{tabular}

DP é o desvio padrão, CV é o coeficiente de variação (\%), Máx. é o valor máximo, Mín. é o valor mínimo.

Org. dos autores.

Na Tabela 11 são apresentados os valores do coeficiente de correlação e determinação entre o teor de Argila + Silte (\%) e o teor de carbono (\%) para a pastagem melhorada e degradada, nas diferentes profundidades de solo. A partir da análise dos dados apresentados observa-se que no geral o teor de carbono aumenta com o aumento da fração Argila + Silte, tanto para pastagem melhorada quanto para pastagem degradada, com uma correlação positiva moderada, no entanto, na pastagem degradada verifica-se uma maior correlação do que na pastagem melhorada. Este aumento do teor de carbono com o aumento do da fração Argila + Silte ocorre provavelmente pela agregação da matéria orgânica com as partículas argila e silte formando os micros e macros agregados do solo os quais impedem ou minimizam as perdas de carbono (PEIXOTO, 1997).

Tabela 11. Coeficiente de correlação (r) e determinação $\left(\mathrm{R}^{2}\right)$ entre a fração Argila+Silte (\%) e teor de carbono

\begin{tabular}{|l|r|r|r|r|}
\hline \multirow{2}{*}{ Profundidade (cm) } & \multicolumn{2}{|c|}{ Pastagem Melhorada } & \multicolumn{2}{c|}{ Pastagem Degradada } \\
\cline { 2 - 5 } & \multicolumn{1}{c|}{$\mathbf{r}$} & \multicolumn{1}{c|}{$\mathbf{R}^{\mathbf{2}} \mathbf{( \% )}$} & \multicolumn{1}{c|}{$\mathbf{r}$} & \multicolumn{1}{c|}{$\mathbf{R}^{\mathbf{2}} \mathbf{( \% )}$} \\
\hline $0-5$ & 0.4695 & 22.04 & 0.6730 & 45.29 \\
\hline $5-10$ & 0.5708 & 32.58 & 0.7378 & 54.43 \\
\hline $10-20$ & 0.6415 & 41.15 & 0.6909 & 47.73 \\
\hline $20-30$ & 0.5571 & 31.03 & 0.6712 & 45.05 \\
\hline
\end{tabular}

Org. dos autores.

Na Tabela 12 são mostrados os valores do coeficiente de correlação e determinação entre a densidade do solo $\left(\mathrm{g} / \mathrm{cm}^{3}\right)$ e o teor de carbono $(\%)$ para a pastagem melhorada e degradada, nas diferentes profundidades de solo. A partir da análise dos dados apresentados observa- -se que o teor de carbono diminui com o aumento da densidade do solo, tanto para pastagem melhorada quanto para pastagem degradada, com uma correlação negativa moderada, no entanto, na pastagem degradada verifica-se uma maior correlação do que na pastagem melhorada. 
Tabela 12. Coeficiente de correlação (r) e determinação $\left(\mathrm{R}^{2}\right)$ entre a densidade do solo $\left(\mathrm{g} / \mathrm{cm}^{3}\right)$ e o teor de carbono $(\%)$

\begin{tabular}{|l|r|r|r|r|}
\hline \multirow{2}{*}{ Profundidade (cm) } & \multicolumn{2}{|c|}{ Pastagem Melhorada } & \multicolumn{2}{c|}{ Pastagem Degradada } \\
\cline { 2 - 5 } & $\mathbf{r}$ & $\mathbf{R}^{\mathbf{2}} \mathbf{( \% )}$ & \multicolumn{1}{c|}{$\mathbf{r}$} & $\mathbf{R}^{\mathbf{2}} \mathbf{( \% )}$ \\
\hline $0-5$ & -0.6104 & 37.26 & -0.5897 & 34.78 \\
\hline $5-10$ & -0.4425 & 19.58 & -0.6883 & 47.38 \\
\hline $10-20$ & -0.5511 & 30.37 & -0.5401 & 29.17 \\
\hline $20-30$ & -0.4700 & 22.09 & -0.5247 & 27.53 \\
\hline
\end{tabular}

Org. dos autores.

\section{CONSIDERAÇÕES FINAIS}

As análises granulométricas mostram que em média as pastagens (melhorada e degradada), ocupam áreas de solo com características físicas parecidas, com predominância nos solos com aproximadamente $40 \%$ de argila. Em média a umidade do solo decresce com o aumento da profundidade para a pastagem melhorada, passando de $26.7 \%$ de umidade na camada 0-5 cm para $24.0 \%$ para a camada de $20-30 \mathrm{~cm}$. Já na pastagem degradada à umidade varia muito pouco com a profundidade, ficando em torno de $19 \%$. Observa-se também que os solos sob pastagem melhorada apresentam em média $5 \%$ a mais de umidade quando comparados com os solos obtidos sob pastagem degradada.

A densidade do solo sob pastagem melhorada é menor do que a dos solos sob pastagem degradada, demonstrando que uma pastagem bem manejada, permite um solo mais estruturado, com maior porosidade, o que favores a infiltração de água da chuva, diminuindo o escoamento superficial. Observa-se também que a densidade aumenta com o aumento da profundidade de coleta do solo, em ambos os tipos de pastagem.

O teor de carbono diminui com a profundidade de coleta do solo, independente da pastagem ser melhorada ou degradada. Verifica-se que em média, a pastagem melhorada apresenta um valor mais elevado de carbono no solo do que a pastagem degradada, em todas as profundidades analisadas.

A camada superficial $(0-5 \mathrm{~cm})$ apresenta o maior teor de carbono, tanto para pastagem melhorada quanto para pastagem degradada. Tendo como valor médio de teor de carbono de $2.60 \%$ para pas- tagem melhorada e $1.90 \%$ para pastagem degradada. Observa-se também que a pastagem melhorada possui em média um valor maior de teor de carbono no solo em todas as profundidades, quando comparado com a pastagem degradada. De maneira geral, o teor de carbono decresce com o aumento da profundidade de coleta do solo, tanto para pastagem melhorada quanto para a pastagem degradada.

Convém destacar que se considerarmos todas as camadas analisadas ( $0-30 \mathrm{~cm}$ de profundidade) a pastagem melhorada possui em média um estoque de carbono de $68.28 \mathrm{Mg} /$ ha enquanto que a pastagem degradada apresenta estoque de $59.35 \mathrm{Mg} / \mathrm{ha}$.

O teor de carbono aumenta com o aumento da fração Argila + Silte, tanto para pastagem melhorada quanto para pastagem degradada, com uma correlação positiva moderada, no entanto, na pastagem degradada verifica-se uma maior correlação do que na pastagem melhorada. Já, o teor de carbono diminui com o aumento da densidade do solo, tanto para pastagem melhorada quanto para pastagem degradada, com uma correlação negativa moderada.

Os dados encontrados no presente trabalho demonstram que uma pastagem melhorada consegue armazenar na profundidade de $0-30 \mathrm{~cm}, 15 \%$ a mais de carbono do que em uma pastagem degradada, ou seja, retira mais carbono da atmosfera e armazena no solo, contribuindo desta forma na redução do aquecimento global (efeito estufa). Chama-se atenção para a pastagem, por ser a categoria de uso antrópico que mais área ocupa na bacia hidrográfica do Rio Paranaíba (41.1\%). Em um cenário onde toda a pastagem degradada fosse convertida em melhorada, a bacia do Rio Paranaíba teria um potencial de aumento do estoque de carbono no solo da ordem de $41 \mathrm{Tg}$. 
A conversão da pastagem degradada para melhorada poderá ser feita usando técnicas de integração lavoura-pecuária-floresta, no entanto, o grande desafio é sensibilizar os pecuaristas para a importância da recuperação das pastagens, os quais poderão contar com a ajuda financeira do Plano de Agricultura de Baixo Carbono (Plano ABC) do Governo Federal.

\section{AGRADECIMENTOS}

Ao Conselho Nacional de Desenvolvimento Científico e Tecnológico (CNPq) por ter concedido bolsa de Produtividade em Pesquisa ao primeiro autor (Processo 302844/2010-4) e a FAPEMIG por ter liberado recursos para a aquisição do Analisador Elementar (CHNS-O) Flash2000, da Thermo Scientific, instalado na FACIP/UFU.

\section{REFERENCIAS}

ANA (Agência Nacional de Águas). Diagnóstico da bacia hidrográfica do rio Paranaíba. Parte A, 2011. Disponível em: http://www.paranaiba.cbh.gov.br/ PRH/RP03-Parte_C.pdf. Acesso em agosto de 2012.

CERRI, C.C.; BERNOUX, M.; CERRI, C.E.P.; LAL, $R$. Challenges and opportunities of soil carbon sequestration in Latin America. In: LAL, R.; CERRI, C.C.; BERNOUX, M.; ETCHEVERS, J.; CERRI, C.E.P. (org.) Carbon sequestration in soils of Latin America. New York, Haworth, p.41-47, 2006.

CERRI, C. E. P.; SPAROVEK, G.; BERNOUX, M.; EASTERLING, W. E.; MELILLO, J. M.; CERRI, C. C. Tropical agriculture and global warming: impacts and mitigation options. Scientia Agricola, v. 64, p. 83-99, 2007. DOI: http://dx.doi.org/10.1590/S010390162007000100013

CHAPUIS LARDY, L.; BROSSARD M.; LOPES ASSAD, M.L.; LAURENT, J.Y. Carbon and phosphorus stocks of clayey Ferralsols in Cerrado native and agroecosystems, Brazil. Agriculture, Ecosystems and Environment, v.92, n. 2, p.147-158, 2002. DOI: http://dx.doi.org/10.1016/S0167-8809(01)00303-6
CORAZZA, E.J.; SILVA, J.E.; RESCK, D.V.S.; GOMES, A.C. Comportamento de diferentes sistemas de manejo como fonte ou depósito de carbono em relação a vegetação de cerrado. Revista Brasileira de Ciência do Solo, Viçosa, v.23, n.2, p.425-432, 1999.

D'ANDRÉA, A.F.; SILVA, M.L.N.; CURI, N.; SIQUEIRA, J.O. \& CARNEIRO, M.A.C. Atributos biológicos indicadores da qualidade do solo em sistemas de manejo na região doCerrado no sul do Estado de Goiás. Revista Brasileira de Ciência do Solo, v.26, p.913-923, 2002.

EMBRAPA. Serviço Nacional de Levantamento e Conservação de Solos. Manual de métodos de análise de solo. $2^{\mathrm{a}}$. Ed., Rio de Janeiro 1997. 212 p.

ESWARAN, H.; VAN DEN BERG, E.; RE$\mathrm{ICH}$, P.F. Organic carbon in soils of the world. Soil Science Society of America Journal, v.57, p.192-194, 1993. DOI: http://dx.doi.org/10.2136/ sssaj1993.03615995005700010034x

FAO. Global forest resources assessement 2005: progress towards sustainable forest management. Roma, 2006. 320 p.

FRAZÃO, L.A.; PICCOLO, M.C.; FEIGL, B.J.; CERRI, C.C. \& CERRI, C.E.P. Inorganic nitrogen, microbial biomass and microbial activity of a sandy Brazilian Cerrado soil underdifferent land uses. Agriculture, Ecosystems \& Environment, v. 26, n.3, p.161-167, 2010. DOI: http://dx.doi.org/10.1016/j. agee.2009.09.003

FREIXO, A. A.; MACHADO, P. L. O. A.; GUIMARÃES, C. M.; SILVA, C. A.; FADIGAS, F. S. Estoques de carbono e nitrogênio e distribuição de frações orgânicas de latossolo do cerrado sob diferentes sistemas de cultivo. Revista Brasileira de Ciência do Solo, Viçosa, v.26, n.2, p.425-434, 2002.

LAL, R., KIMBLE; J. M., FOLLETT, R. F.; COLE, C. V. The potential of U.S. cropland to sequester carbon and mitigate the greenhouse effect. Sleeping Bear Press, 1998. 
MAIA, S.M.F.; OGLE, S.M.; CERRI, C.E.P. \& CERRI, C.C. Effect of grassland management on soil carbon sequestration in Rondônia and Mato Grosso states, Brazil. Geoderma, v.149, n. 01, p.84-91, 2009. DOI: http://dx.doi.org/10.1016/j.geoderma.2008.11.023

MMA (Ministério do Meio Ambiente.) Mapa de cobertura vegetal dos biomas brasileiros. 2007. Disponível em: http://www.mma.gov.br/ sitio/index.php?ido=conteudo. monta\&id Estrutura=72\&idMenu=3813. Acesso em: 08 jul. 2009.

MORAES, A.; PELISSARI, A.; ALVES, S.J.. Integração Lavoura-Pecuária no Sul do Brasil. In: MELLO, N.A., ASSMANN, T.S. (Eds.). I ENCONTRO DE INTEGRAÇÃO LAVOURA-PECUÁRIA NO SUL DO BRASIL. Anais... (s/i). p.3-42. 2002.

NELSON, D.W. \& SOMMERS, L.E. Total carbon, organic carbon, and organic matter. In: BLACK, C.A., ed. Methods of soil analysis. Part 3. Chemical methods. Madison, Soil Science of America and American Society of Agronomy, p.961-1010, 1996. DOI: http:// dx.doi.org/10.2136/sssabookser.5.3.c34

NOBRE C.A. \& GASH J.H.C., Desmatamento e clima: o maior estudo já feito na Amazônia. Ciência Hoje, v.22, n.128, p.32-41, 1997.

OGLE, S.M.; CONANT, R.T.; PAUSTIAN, K. Deriving grassland management factors for a carbon accounting approach developed by the Intergovernmental Panel on Climate Change. Environmental Management, v.33, n. 2, p. 474-484, 2004. DOI: http:// dx.doi.org/10.1007/S00267-003-9105-6

OLIVEIRA, O. C. de; OLIVEIRA, I. P. de; ALVES, B. J. R; URQUIAGA, S.; BODDEY, R. M. Chemical and biological indicators of decline/degradation of Brachiaria pastures in the Brazilian Cerrado. Agriculture, Ecosystems and Environment, Amsterdam, v. 103, n. 2, p. 289-300, 2004. DOI: http://dx.doi.org/10.1016/j. agee.2003.12.004
PEIXOTO, R.T.G. Matéria orgânica e a dinâmica das cargas elétricas dos solos: processos e conseqüências. XXVICONGRESSO BRASILEIRO DE CIÊNCIADO SOLO, Rio de Janeiro, 20 a 26 de julho de 1997. Anais... Rio de Janeiro, SBCS/EMBRAPA - CNPS, 1997.

RANGEL, O.J.P.; SILVA, C.A. Estoques de carbono e nitrogênio e frações orgânicas de latossolo submetido a diferentes sistemas de uso e manejo. Revista Brasileira de Ciência do Solo, Viçosa, v.31, p.16091623, 2007. DOI: http://dx.doi.org/10.1590/s010006832007000600037

ROSCOE, R.; BUURMAN, P.; VELTHORST, E.J. \& VASCONCELLOS, C.A. Soil organic matter dynamics in density and particle size fractions as revealed by the ${ }^{13} \mathrm{C} /{ }^{12} \mathrm{C}$ isotopic ratio in a Cerrado's oxisol. Geoderma, v.104, p.185-202, 2001. DOI: http://dx.doi. org/10.1016/s0016-7061(01)00080-5

ROSENDO, J.S.; ROSA, R. Comparação do estoque de $\mathrm{C}$ estimado em pastagem e vegetação nativa de cerrado. Sociedade \& Natureza, v.24, n.2, p.359379, 2012. DOI: http://dx.doi.org/10.1590/S198245132012000200014

SANO, E.E.; ROSA, R.; BRITO, J.L.S.; FERREIRA, L.G. Mapeamento do uso do solo e cobertura vegetal - Bioma Cerrado - Ano base 2002. Brasília, MMA/ SBF, 2010.

SANTOS, A.B.; QUESADA, C.A.N.; SILVA, G.T.; MAIA, J.M.F.; MIRANDA, H.S.; MIRANDA, A.C.; LLOYD, J. High rates of net ecosystem carbono assimilation by brachyaria pasture in Brazilian Cerrado. Global Change Biology, v.10, p. 1-9, 2004.

SILVA, J.E. da; RESCK, D.V.S.; CORAZZA, E.J.; VIVALDI, L. Carbon storage in clayey Oxisol cultivated pastures in the "Cerrado" region, Brazil. Agriculture, Ecosystems and Environment, v.103, p.357-363, 2004. DOI: http://dx.doi.org/10.1016/j.agee.2003.12.007 
SILVA, C.A. Mineralização de nitrogênio e enxofre e caracterização de substâncias húmicas em solos brasileiros por 13C-RMN e cromatografia por exclusão de tamanho. 1997, Tese (Doutorado em Agronomia), Universidade Federal de Lavras. Lavras, 1997. 82p.

SOON, Y. K., ABBOUD, S. A comparison of some methods for soil organic carbon determination. Communications in Soil Science and Plant Analysis, v.22, p. 943-954, 1991. DOI: http://dx.doi. org/10.1080/00103629109368465

TARRÉ, R.; MACEDO, R.; CANTARURI, R. B.; REZENDE, C. de P.; PEREIRA, J.,M.; FERREIRA, E.; ALVES, B. J. R.; URQUIAGA, S.; BODDEY, R. M. The effect of the presence.of legume on a Brachiaria humidicola pasture. Plant and Soil. v.234, p. 15-26, 2001. DOI: http://dx.doi. org/10.1023/A:1010533721740

WALKLEY, A. e BLACK, I.A. An examination of the Degtjareff method for determining soil organic matter and a proposed modification of the chromic acid titration method. Soil Science, v. 37, p.29-38, 1934.

YEOMANS, J.C. e BREMNER, J.M. A rapid and precise method for routine determination of organic carbon in soil. Communications in Soil Science and Plant Analysis, v.19, p.1467-1476, 1988. DOI: http://dx.doi. org/10.1080/00103628809368027 
